\title{
Assuring Mechanical Reliability of Ceramic Components
}

\author{
John E. RITTER, Jr. \\ Mechanical Engineering Department, \\ University of Massachusetts \\ Amherst, MA 01003, USA
}

\begin{abstract}
A reliability analysis for structural ceramic components must take into account the variability and time-dependency of strength exhibited by these materials. The concepts and techniques of fracture mechanics theory can be used for these purposes. Fracture mechanics theory appropriate to assessing the mechanical reliability of structural ceramics is reviewed and the application of the theory to assuring the safety of a vitreous-bonded abrasive is discussed as an example of a case where relatively large tensile stresses are imposed on a ceramic body.
\end{abstract}

[Received December 10, 1984]

\section{セラミック材料における機械的な信頼性の保証}

John E. Ritter, Jr.

(マサチューセッツ大学 機械工学科)

構造用セラミック材料についての信頼性の解析を行うためには, これらの材料が示す強度の変動 性之時間依存性を考慮する必要がある.この目的には破壊力学理論の概念と手法を用いることがで きる．構造用セラミックスの機械的な信頼性を評価するのに適した破壊力学理論を概説し，この理 論を, 比較的大きな引っ張り応力がかかる場合の一例としてガラスボンド砥石の安全性の保証に応 用する。

(1984 年 12 月 10 日受付)

Key-words : Mechanical reliability, Ceramics abrasive, Fracture mechanics

\section{Introduction}

Design problems arise for two reasons when ceramics are used as structural components : (1) The strength is not a well-defined quantity but can vary considerably depending on the manufacturing and surface finishing process used in fabricating the ceramic; (2) The strength in the presence of moisture is time dependent so that these materials can exhibit a time-delayed failure. This scatter and time-dependence of strength, so typical of most ceramic materials, occurs because of the presence of small cracks or crack-like flaws in these materials. When subjected to an applied tensile stress, these flaws act as stress concentrators and fracture occurs if the concentrated stress reaches a critical value. Scatter in the strength of ceramic materials is a consequence of the scatter in the size and distribution of the most critical flaw in the ceramic. The time dependency of strength results from subcritical crack growth, which gradually lengthens the crack until it reaches critical dimensions, at which point failure occurs. The time delay to failure is the time required for the crack to go from a subcritical to a critical size under a given stress.

Methods of dealing with design problems involving ceramic materials have been developed over the past 10 years through the application of the concepts of fracture mechanics ${ }^{1-3}$. With these techniques ceramics can be devised that allow rational designing under tensile stress. This new understanding offers possibilities of designing ceramics for applications in such diverse areas as space shuttle tiles ${ }^{4}$, electronic substrates ${ }^{51}$, and engine components ${ }^{6}$.

A proper reliability analysis for ceramic materals must take into account the variability and time dependency of their strength. The aim of this 
paper is to review fracture mechanics theory appropriate for designing structural components with ceramic materials and to describe the successful application of this theory in assuring the reliability of vitrified grinding wheels in service.

\section{Background}

\subsection{Fast fracture reliability}

A critical problem in attempting to use ceramic materials in demanding structural applications is the uncertainty about the stresses to which they can be safely subjected. These materials rarely, if ever, exhibit a characteristic failure stress. This stress depends on the nature and distribution of microscopic flaws that intensify the stress locally, and fracture initiates at a single "worst" flaw when the local stress intensity factor reaches a critical value. These critical flaws may be an intrinsic feature of the microstructure : a pore, a weak grain boundary, an inclusion, or a large grain $^{7}$. They may also be an extrinsic scratch, pit, or crack introduced in surface finishing or by abusive handling or a consequence of service ${ }^{8)}$. Because of the generally low fracture toughness of ceramics, these critical flaws are often a few micrometers or less in size.

The distribution of critical flaws is generally determined by measuring the "fast fracture" strength distribution. Flaw size $(a)$ and fast fracture strength $(S)$, i. e. in the absence of subcritical crack growth, are related through the well-known fracture mechanics relationship:

$$
S=\frac{K_{\mathrm{Ic}}}{Y \sqrt{a}}
$$

where $K_{\text {Ic }}$ is the critical stress intensity factor and $Y$ is a constant related to the loading and flaw geometry. The statistics of fracture strength thus relate to the large flaw size extreme of the flaw population. The majority of the mathematical descriptions of fracture statistics presently available are based on the weakest link concept which simply states that the entire body will fail when the stress at any defect is sufficient for unstable crack propagation of that defect. The Weibull distribution is by far the most popular because of its mathematical simplicity and its relative good success in describing strength data ${ }^{91-11}$.

The two-parameter Weibull expression for the fast fracture reliability $(R)$, i. e. the reliability in the absence of subcritical crack growth, is for volume flaws controlling strength :

$$
R=1-F=\exp \left[-\int_{V}\left(\frac{\sigma}{\sigma_{0}}\right)^{m} \mathrm{~d} V\right]
$$

were $F$ is the failure probability, $m$ is the Weibull modulus, $\sigma_{0}$ is the Weibull scaling constant, and $V$ is the total volume under stress $\sigma$. The Weibull modulus is a measure of the scatter in the strength distribution, similar to the standard deviation of the normal distribution, where a small $m$ represents a large degree of scatter. Most ceramic materials have $m$ values in the range of 5 to $15^{7}$. The Weibull scaling parameter is an indirect measure of the average strength.

For bodies under uniform tension, the integration of Eq. ( 2 ) is straightforward, but for the general case where stress in a body is a function of position, the integration becomes more complex. In general, Eq. ( 2 ) can be integrated to give ${ }^{12), 13)}$ :

$$
R=\exp \left[-L_{V} V\left(\sigma_{M} / \sigma_{0}\right)^{m}\right]
$$

where $\sigma_{M}$ is the maximum stress in the body and $L_{v}$ is the load factor that is defined by:

$$
L_{V}=\int_{V}\left(\frac{\sigma}{\sigma_{M}}\right)^{m} \frac{\mathrm{d} V}{V}
$$

Note that the integrations of Eqs. (2) and (4) are carried out only over the volume where tensile stresses are present since it is assumed that compressive stresses do not contribute to the failure. Also, if surface flaws control failure, Eqs. (2) and (4) can be written in terms of surface area and the corresponding equations integrated over area instead of volume.

For bodies where a multiaxial stress distribution exists, it is generally assumed that the reliability in each principal stress direction is independent of one another ${ }^{9)-11}$. Hence, the total fast fracture reliability $\left(R_{T}\right)$ is the product of the reliability for the principal stresses applied individually :

$$
R_{T}=R_{1} R_{2} R_{3}
$$

By comparing Eqs. ( 5 ) and (3), it can be deduced that the total load factor for multiaxial loading is the sum of the individual load factors.

For uniaxial loading $L_{\mathrm{v}}$ is simply one. For any other stress distribution $L_{\mathrm{v}}$ is always less than one and dependent on $m$. Although Eq. ( 4 ) can be integrated for any stress distribution that has a known analytical form, for stressed bodies with complicated geometry and/or loading it is generally easier to divide the body into a number of elements, each of which is small enough to warrant the assumption of constant stress through- 
out the element. Considering one element and one principal stress, the reliability is:

$$
R_{i j}=\exp \left[-\left(\frac{\sigma_{i j}}{\sigma_{0}}\right)^{m} V_{j}\right]
$$

where the subscripts $i$ and $j$ represnt the principal stress and element, respectively, under consideration. The total fast fracture reliability is then obtained from the product of all the reliabilities considering the three principal stresses (but neglecting compressive stresses) in each element or in mathematical notation:

$$
R_{T}=\prod_{i=1}^{3} \prod_{j=1}^{j} R_{i j}
$$

where $J$ is the total number of elements.

The Weibull modulus $m$ and scaling constant $\sigma_{0}$ are estimated by measuring the fracture strengths of a number of statistically identical test specimens. The strengths are ordered from weakest to strongest, with 'each assigned a failure probability based on its ranking, $h$, as follows ${ }^{11,12)}$ :

$$
F=\frac{h-0.5}{H}
$$

where $H$ is the total number of data points. Although several techniques, such a maximum likelihood and method of moments, can be used to determine $m$ and $\sigma_{0}$, the most straightforward is a simple linear regression of the data ${ }^{11), 12)}$. Equation (3) can be rearranged in a linear form :

$$
\ln \ln \frac{1}{R}=m \ln S+\ln \frac{L_{v} V}{\sigma_{0}^{m}}
$$

where the fracture strength $S$ is equivalent to the maximum tensile stress at fracture, $\sigma_{m}$.

The most widely used strength tests are either 3 -point or 4-point bending. The volume load factor for 3-point bending is ${ }^{11,12)}$ :

$$
L_{v 3}=\frac{1}{2(m+1)^{2}}
$$

For 4-point bending the load factor is:

$$
L_{v 4}=\frac{(a / b) m+1}{2(m+1)^{2}}
$$

where $a$ is the inner and $b$ the outer span. Equation (11) correctly reduces to Eq. (10) for 3 -point bending where the inner span $a$ is zero. In the case where failure is controlled by surface flaws, Eqs. (10) and (11) can be converted to the corresponding area load factor $\left(L_{A}\right)$ by ${ }^{12)}$ :

$$
L_{A}=L_{v}\left(\frac{m w}{w+h}+1\right)
$$

where $w$ and $h$ are the specimen width and height, respectively. For other test geometries, the reader is referred to references 9) to 13) for the appropriate load factor.

Reliability predictions are unfortunately quite sensitive to the uncertainty in the experimentally determined Weibull parameters and $m$ and $\sigma_{0}$. Although experimental errors can be minimized by well-designed experiments, inherent in each experiment is uncertainty due to statistical reproducibility ${ }^{14)}$. Statistical reproducibility is due to random sampling errors that result from the finite number of samples used in testing. Generally, at least 50 samples are needed to minimize the uncertainty in the Weibull parameters ${ }^{14}$.

\subsection{Fatigue reliability}

Time dependent failure, i.e. fatigue, of ceramics occurs from the stress-dependent growth of preexisting flaws. Quantitative estimates of the amount of crack growth during a stress cycle can be used to evaluate the strength of a component at any point in the cycle. The rate of strength degradation can be obtained by differentiating Eq. (1) with respect to time:

$$
\begin{aligned}
\frac{\mathrm{d} S}{\mathrm{~d} t} & =-\left(\frac{K_{\mathrm{Ic}}}{2 Y}\right) a^{-3 / 2} \frac{\mathrm{d} a}{\mathrm{~d} t} \\
& =-\frac{Y^{2}}{2 K_{\mathrm{Ic}}^{2}} S^{3} V
\end{aligned}
$$

where $V$ is the rate of crack growth. This subcritical crack velocity is generally assumed to be dependent on the applied stress intensity factor $\left(K_{\mathrm{I}}\right)$ by $^{1-3)}$ :

$$
V=A\left(K_{\mathrm{I}} / K_{\mathrm{Ic}}\right)^{N}
$$

where $A$ and $N$ are material/environment constants. Note that $N$ generally has a value greater than 10 for ceramic materials ${ }^{1,3}$. By definition the stress intensity factor is :

$$
K_{\mathrm{I}}=Y \sigma \sqrt{a}
$$

Substituting Eqs. (14) and (15) into (13) and integrating gives a relationship between the initial strength $\left(S_{i}\right)$ and the final strength $\left(S_{f}\right)$ as follows :

$$
S_{f}^{N-2}=S_{i}^{N-2}-\frac{1}{B} \int_{0}^{t} \sigma(t)^{N} \mathrm{~d} t
$$

where $B=\frac{2 K_{\mathrm{Ic}}{ }^{2}}{(N-2) A Y^{2}}$ and is a material / environment constant.

Thus, from Eq. (16) the amount of strength degradation can be determined for any stress cycle provided the applied stress $\sigma$ is known as a function of time. Failure occurs when the applied stress equals the strength $S_{f}$. For the important case of a constant applied stress, $\sigma(t)=\sigma_{a}$, Eq. (16) gives for failure: 


$$
S_{i}^{N-2}=\sigma_{a}^{N-2}\left(1+\frac{\sigma_{a}^{2} t_{f}}{B}\right)
$$

where $t_{f}$ equals time to failure. The fast fracture reliability $(R)$ is related to $\sigma_{a}$ and the fatigue reliability $\left(R_{f}\right)$ to $S_{i}$ by the following equations, respectively :

$$
\begin{aligned}
& R=\exp \left[-L_{v} V\left(\sigma_{a} / \sigma_{0}\right)^{m}\right] \\
& R_{f}=\exp \left[-L_{v} V\left(S_{i} / \sigma_{0}\right)^{m}\right]
\end{aligned}
$$

Substituting Eq. (18) into (17) gives after some manipulation :

$$
\ln R_{f}=(\ln R)\left(1+\frac{\sigma_{a}^{2} t_{f}}{B}\right)^{\frac{m}{N-2}}
$$

Equation (19) shows how the fast fracture reliability is decreased by fatigue, i. e., subcritical crack growth. When the failure time equals zero, the fatigue reliability is equal to the fast fracture reliability. Equation (19) also shows how the experimental parameters $N, B$ and $m$ and the service conditions $\sigma_{a}$ and $t_{f}$ affect the fatigue reliability.

As with fast fracture reliability, the fatigue reliability of a component under a constant applied stress can be calculated more easily by dividing the body into a number of elements, each of which is small enough to warrant the assumption of constant stress throughout the element. Considering one element and one principal stress, the fatigue reliability is:

$$
\ln R_{i j f}=\left(\ln R_{i j}\right)\left(1+\frac{\sigma_{i j}^{2} t_{f}}{B}\right)^{\frac{m}{N-2}}
$$

The total fatigue reliability is obtained by taking the product of all the individual reliabilities:

$$
R_{T f}=\prod_{i=1}^{3} \prod_{j=1}^{J} R_{i j f}
$$

It is important to note that the fatigue reliability can in general be calculated from Eq. (16) for any given stress cycle in service and the results put in terms of an "equivalent" constant stress; hence, reliability can still be expressed by an equation of the form of Eq. (20). The reader is referred to reference 15 for the solution of Eq. (16) for an arbitrary stress cycle.

From Eq. (20) it can be seen that the fatigue reliability is dependent on the fatigue parameters $N$ and $B$. These parameters are most easily determined by measuring the fracture strength of a set of specimens at several different stressing rates in a simulated service environment ${ }^{14}$. The fracture strength in a fatigue environment $\left(\sigma_{f}\right)$ is related to the stressing rate $(\dot{\sigma})$ by ${ }^{14)}$ :

$$
\sigma_{f}^{N+1}=B(N+1) S_{i}^{N-2} \dot{\sigma}
$$

Therefore, by plotting $\ln \sigma_{f}$ vs $\ln \dot{\sigma}$, the slope of the regression line gives $N$ and the intercept gives $B$, knowing the fracture strength of the samples in an inert environment where no subcritical crack growth occurs ${ }^{14)}$. Just as fast fracture reliabilities are dependent on the number of samples used to determine $m$ and $\sigma_{0}$, fatigue reliabilities are dependent on the number of samples used in the stressing rate tests. To minimize the uncertainty in the parameters $N$ and $B$, at least 100 samples must be utilized and the stressing rate range must be at least 3 orders of magnitude ${ }^{14)}$.

\subsection{Proof testing}

Because ceramics exhibit a wide spread in strength values, the allowable stress or lifetime in service is quite low if small failure probabilities are required. Proof testing offers one means of increasing the reliability and / or design stress for ceramics since proof testing eliminates the weaker specimens before they are put into service. For a typical proof test, a component is loaded at a constant rate, $\dot{\sigma}_{1}$, held at the proof stress, $\sigma_{p}$, for a time $t_{p}$, and then unloaded at a constant rate, $\dot{\sigma}_{u}$. The time for loading, $t_{1}$, and unloading, $t_{u}$, are given by $t_{1}=\sigma_{p} / \dot{\sigma}_{1}$ and $t_{u}=\sigma_{p} / \dot{\sigma}_{u}$. Integrating Eq. (16) for this stress cycle then gives the following equation for the final strength of any component that does not break during the proof test :

$$
S_{f}^{N-2}=S_{i}^{N-2}-D_{p} / B
$$

where $D_{p}=\sigma_{p}^{N} t_{p}+\sigma_{p}^{N+1}\left(1 / \dot{\sigma}_{1}+1 / \dot{\sigma}_{u}\right) /(N+1)$ and the constants $N$ and $B$ are those appropriate to the proof test environment. The term $D_{p} / B$ represents the strength degradation that occurs during the proof test cycle.

Weibull statistics can be incorporated into Eq. (23) by writing the initial strength in terms of its Weibull distribution:

$$
Q_{i}=L_{v} V\left(S_{i} / \sigma_{0}\right)^{m}
$$

where $Q_{i}=\ln R_{i}^{-1}=\ln \left(1-F_{i}\right)^{-1}$. The initial failure probility (as characterized by $Q_{i}$ ) can be related to the failure probability after proof testing (as characterized by $Q_{f}$ ) and the failure probability of the component that just fails during the proof test (characterized by $Q_{p}$ ) by ${ }^{15)}$ :

$$
Q_{i}=Q_{f}+Q_{p}
$$

By substituting Eqs. (24) and (25) into Eq. (23), the strength after proof tesing can be related to failure probability $\left(Q_{f}\right)$ by ${ }^{15)}$ : 


$$
\begin{aligned}
\left(S_{f} / \sigma_{0}\right)^{N-2}= & \left(\frac{Q_{f}+Q_{p}}{L_{v} V}\right)^{\frac{N-2}{m}}-\left(\frac{Q_{p}}{L_{v} V}\right)^{\frac{N-2}{m}} \\
& +\left(\frac{S_{\min }}{\sigma_{0}}\right)^{N-2}
\end{aligned}
$$

where $S_{\min }$ is the minimum strength of a sample that just passes the proof test. $S_{\min }$ has a lower bound of zero and an upper bound of $\sigma_{p}$ and has been shown to depend on the unloading rate by :

$$
S_{\min }=\left[\dot{\sigma}_{u} B(N-2)\right]^{1 / 3}[3 /(N+1)]^{\frac{1}{N-3}}
$$

The failure probability in the proof test can be predicted from Eq. (23) since for the sample that just passes the proof test the $S_{f}$ term is negligible with respect to the $S_{i}$ term and $Q_{i} \approx Q_{p}$ so that:

$$
Q_{p}=L_{v} V \sigma_{0}^{-m}\left(\frac{D_{p}}{B}\right)^{\frac{m}{N-2}}
$$

It is significant to note that the strength after proof testing is truncated at $S_{\min }$ and will be greater than the initial strength at all levels of failure probability if $m<N-2$. By replacing $S_{i}$ by $S_{f}$ in Eq. (17) and then substituting in Eq. (26), the failure time after proof testing as a function of reliability (or failure probability) can be determined for any service condition.

\section{Application}

Although vitrified grinding wheels can have relatively large tensile stresses imposed on them as a consequence of their being spun at high speed, they have been used in industry for over a century. Past and current manufacturing standards demonstrate a high level of safety of these products. This superb safety record has been achieved in part due the manufacturer's use of an internally imposed "safety factor". This safety factor generally requires that vitrified grinding wheels be designed to have a strength 3 to 4 times the stress found in service. In addition, as a safeguard against quality variations and abuse in service, many wheels are proof tested to at least 1. 5 times their allowed service speed. These empirical criteria of acceptance have proved satisfactory to both makers and users of grinding wheels over the years. But demands for higher speeds and longer lifetimes dictate that a more scientific and less pragmatic approach to assuring mechanical reliability be adopted.

There have been several studies ${ }^{17)-19)}$ on the strength and fatigue behavior of vitrified-bonded abrasive materials. These studies showed that the strength and fatigue results could be explained by using the fracture mechanics principles discussed in the previous section. The purpose of this section is to describe the application of a reliability analysis to assure against the failure of vitrified grinding wheels in service. The strength and fatigue data ${ }^{17)}$ of vitrified-bonded abrasive specification 2A601-K4-V9676(VGW2) will be used in this analysis.

To test the validity of Weibull statistics, strengths determined in air with 4-point bending were used to predict the strength of wheels (50.8 $\times 2.5 \times 12.7 \mathrm{~cm})$ that were accelerated up to failure in a spin burst test ${ }^{17}$. From Eq. (19) the strength of a wheel specimen $\left(S_{w}\right)$ at a given level of failure probablity can be predicted from the corresponding 4-point bend strength $\left(S_{4}\right)$ by :

$$
S_{w}=S_{4}\left(\frac{L_{v 4} V_{4}}{L_{v w} V_{w}}\right)^{1 / m}
$$

With Eq. (23) and the corresponding expression for area, the strength distribution of the wheels is compared to predictions in Fig. 1. Note that the loading factors appropriate to the 4-point bend test are given by Eqs. (10) to (12) and those for the spin test were derived by substituting the radial and tangential stress distributions into Eq. (11) (and the corresponding equation based on area) and then numerically integrating the result-

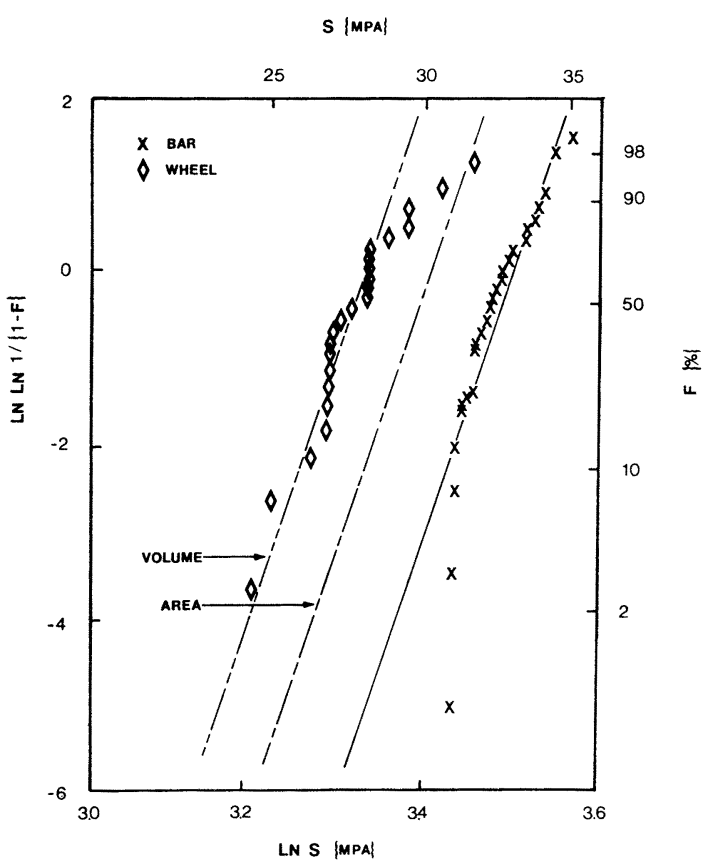

Fig. 1. Comparison of predicted wheel bursting strengths for wheel specification 2A601-K4-V9676 in air based on four-point bending strength data, assuming that the strength controlling flaws are either related to volume or surface area. 


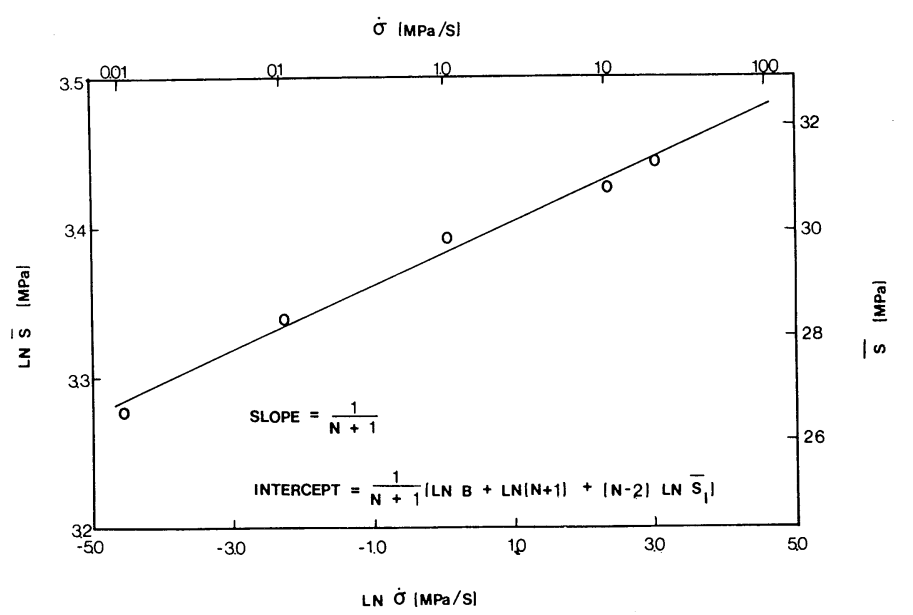

Fig. 2. Median fracture strength as a function of stressing rate for vitrified grinding wheel specification 2A601-K4-V9676 in an aqueous coolant at $35^{\circ} \mathrm{C}$.

ing equation ${ }^{20)}$. The good agreement between the actual spin burst data and the predictions based on volume is evident and indicates that volume flaws control the strength of this vitrified-bonded wheel under centrifugal loading.

To determine the effect that fatigue has on the reliability of a vitrified-bonded grinding wheel in service, the fatigue parameters $N$ and $B$ were measured by 4 -point bending in an aqueous coolant at $35^{\circ} \mathrm{C}$ as a function of stressing rate ${ }^{17}$.

Figure 2 summarizes these results, where $N$ and $B$ are calculated to be 46.2 and $2.2 \times 10^{-3}$ $\mathrm{MPa}^{2} \cdot \mathrm{s}$, respectively. The inert strength of these samples was measured in liquid nitrogen and a Weibull analysis of the data gave for the Weibull parameters $m=23.7$ and $\sigma_{0}=33.05 \mathrm{MPa}$ (based on assuming volume flaws are strength controlling).

Using the above data, a reliability analysis was carried out, assuming volume flaws controlling failure for a grinding wheel $91.4 \times 2.5 \times 30.5 \mathrm{~cm}$ in size operating at a constant outer periphery speed. For this analysis the volume of the wheel was divided into 10 elements consisting of 10 concentric annual rings. On the basis of Eq. ( 7 )

Table 1. Reliability of a Vitrified Grinding Wheel $(91.4 \times 2.5 \times 30.5 \mathrm{~cm})$ operating at a constant outer periphery speed.

\begin{tabular}{cccccc}
\hline $\begin{array}{c}\text { Periphery } \\
(\mathrm{m} / \mathrm{s})\end{array}$ & $\begin{array}{c}\text { speed } \\
\langle\mathrm{rpm}\rangle\end{array}$ & $R_{\mathrm{T}}$ & $R_{\mathrm{Tf}}$ & $\begin{array}{c}\text { Spin test } \\
\text { factor }\end{array}$ & $R_{\mathrm{TP}}$ \\
\hline 45.72 & $\langle 955\rangle$ & $\sim 1.0$ & $1-7 \times 10^{-15}$ & 1.33 & $\sim 1.0$ \\
63.50 & $\langle 1326\rangle$ & $1-7 \times 10^{-15}$ & $1-2 \times 10^{-8}$ & 1.35 & $1-2 \times 10^{-7}$ \\
76.20 & $\langle 1592\rangle$ & $1-3 \times 10^{-10}$ & $1-2 \times 10^{-4}$ & 1.37 & $1-7 \times 10^{-4}$ \\
\hline
\end{tabular}

the initial reliability $\left(R_{T}\right)$ was calculated as a function of wheel speed as summarized in Table 1. It can be seen that the initial reliability is essentially one for all wheel speeds considered. To calculate the fatigue reliability $\left(R_{T f}\right)$ from Eq. (19) it was assumed that the service lifetime of the wheel was 6 weeks $\left(3.6 \times 10^{6} \mathrm{~s}\right)$. The applied stress in service was calculated based on the conservative assumption that the tensile stress in the wheel at its stub size (the maximum outside diameter of the wheel before it is replaced) is present throughout its life. The stub size in the present example was assumed to be $45.7 \mathrm{~cm}$. Table 1 shows that fatigue effects can dramatically decrease the reliability so that the likelihood of fatigue failure becomes a distinct possibility at speeds greater than $1500 \mathrm{rpm}$.

To use wheels at very high speeds, Table 1 shows that proof testing ${ }^{17)}$ becomes essential to assure against fatigue failure for the given lifetime of a wheel used at constant peripheral speed. The value of proof testing is that it can assure that the minimum strength after proof testing is equal to proof stress $\left(\sigma_{p}\right)$. Thus, the minimum lifetime after proof testing is from Eq. (17) to good approximation $^{17)}$ :

$$
t_{\min }=B \sigma_{a}^{-2}\left(\frac{\sigma_{\rho}}{\sigma_{a}}\right)^{N-2}
$$

The proof stress can be conservatively calculated from Eq. (24) by calculating the proof stress required for the element that contains the maximum applied stress present at the stub size of the wheel. For volume controlling flaws this element is the one at the inner bore. The spin test factor is then calculated by determining the proof test speed necessary to achieve this proof stress in the inner bore element in a new wheel $(91.4 \times 2.5 \times$ $30.5 \mathrm{~cm})$ and then dividing this proof test speed by the operating speed ${ }^{17}$. The predicted spin test factors are given in Table 1 as a function of wheel speed. These predicted spin test factors are all less than the minimum standard of 1.50 used in industries in Japan and the United States. Therefore, it is believed that the overspeed proof test value currently used for this vitrified-bonded grinding wheel is quite adequate to prevent fatigue failure in service. Also, included in Table 
1 is the estimated reliability of a new wheel subjected to the required overspeed proof test $\left(R_{T f}\right)$. Thus, it is seen that a 1.37 spin test factor would eliminate only 7 wheels out of 10,000 , yet it would assure against fatigue failure of a wheel spinning at a constant $76.2 \mathrm{~m} / \mathrm{s}$ at its outer periphery.

\section{Summary}

Figure 3 is a schematic flow diagram for a reliability analysis of ceramic structural components. First, the strength of a number of specimens (at least 50) is measured under inert test conditions, i.e. in absence of subcritical crack growth. From a Weibull analysis of this data base and a stress analysis of the component, the fast fracture reliability can be calculated. The fatigue reliability is then calculated based on the fatigue parameters determined by measuring the strength of a group of specimens (at least 100) as a function of stressing rate in a simulated service environment. If the calculated reliabilities are too low, the design of the component can then be modified iteratively until an acceptable level of reliability is reached or proof testing can be used

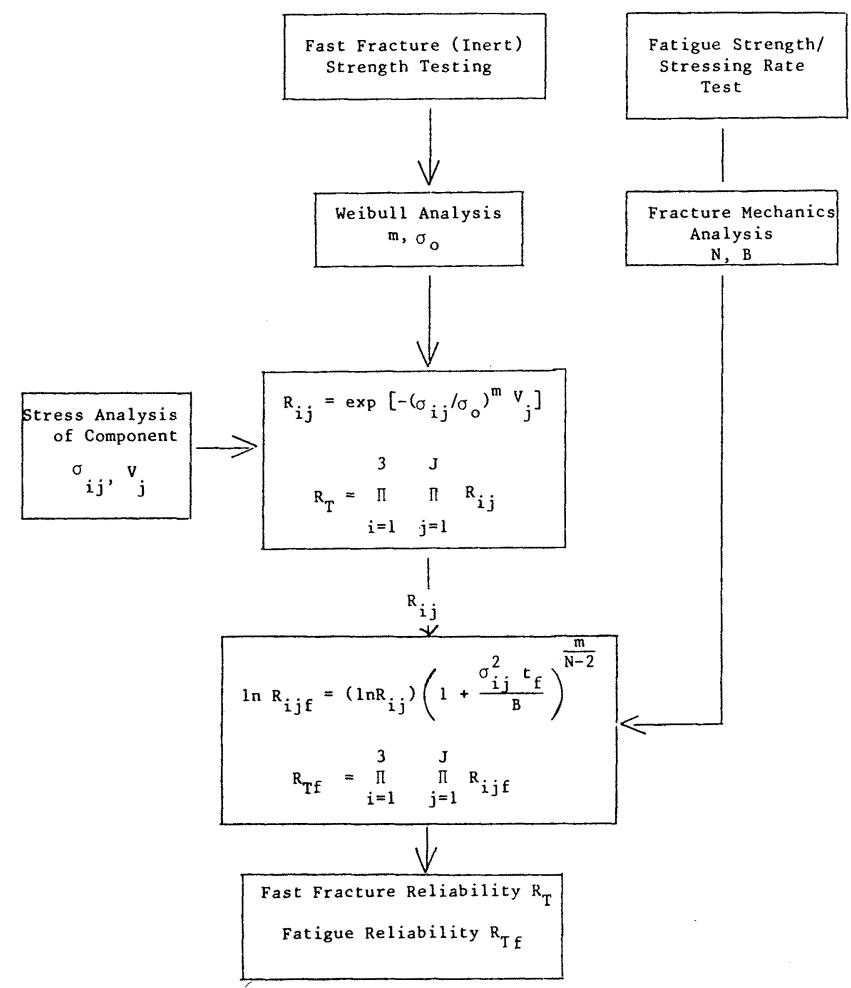

Fig. 3. Flow diagram for reliability analysis assuming that volume flaws control failure. to assure aginst failure in service.

\section{References}

1) J.E. Ritter, "Assessment of Reliability of Ceramic Materials", pp. 227-51 in Fracture Mechanics of Ceramics, Vol.5, Eds. R. C. Bradt, A. G. Evans, D. P. H. Hasselman and F. F. Lange, Plenum Press, NY (1984).

2) S.M. Wiederhorn, "A Probabilistic Framework for Structural Design”, pp. 197-226, ibid.

3) S.W. Freiman, "Fracture Mechanics of Glass", pp. 21-78 in Glass, Science and Technology, Eds. D. R. Uhlmann and N. J. Kreidl, Academic Press, NY (1980).

4) D. J. Green, J.E. Ritter and F.F. Lange, "Fracture Behavior of Low-Density Fibrous Ceramics, J. Am. Ceram. Soc., 65, 141-46 (1982).

5) J.W. Humenik and J.E. Ritter, "Susceptibility of Alumina Substrates to Stress Corrosion Cracking During Wet Processing", Am. Ceram. Soc. Bull., 59, 1205-11 (1980).

6) (a) G. Fisher, "Advanced Ceramics Continue Progress to Products", Am. Ceram. Soc. Bull., 63( 2 ), 249-52 (1984).

(b) D. L. Hartsock and A.F. McLean, "What the Designer with Ceramics Needs," pp. 266-70, ibid.

7) J.E. Ritter and R.W. Davidge, "Strength and Its Variability in Ceramics with Particular Reference to Alumina", J. Am. Ceram. Soc., 67( 6 ), 432-37 (1984).

8) D. B. Marshall, "Surface Damage in Ceramics : Implications for Strength Degradation, Erosion, and Wear", pp. 635-56 in Nitrogen Ceramics, Ed. F.L. Riley, Nijhoff, The Hague (1983).

9) G. G. Trantina and C.A. Johnson, "Spin Testing of Ceramic Materials", pp. 177-88 in Fracture Mechanics of Ceramics, Vol. 3., Eds. R. C. Bradt, D. P. H. Hasselman and F. F. Lange, Plenum Press, NY (1978).

10) M. Srinivasan and S.G. Seshadri, "Probabilistic Design and Reliability of Silicon Carbide Ceramics", J. Mech. Design, 104, 635-42 (1982).

11) (a) D.G.S. Davies, "The Statistical Approach to Engineering Design in Ceramics", Proc. Brit. Ceram. Soc., 22, 429-52 (1973).

(b) P. Stanley, H. Fessler and A.D. Sivill, “ An Engineer's Approach to the Prediction of Failure Probability of Brittle Components", Proc. Brit. Ceram. Soc., 22, 453-87 (1973).

12) C. A. Johnson, "Fracture Statistics of Multiple Flaw Distributions", pp. 365-86 in Fracture Mechanics of Ceramics, Vol.5, Eds. R. C. Bradt, A.G. Evans, D. P. H. Hasselman and F.F. Lange, Plenum Press, NY (1984).

13) N.A. Weil and I. M. Daniel, "Analysis of Fracture Probabilities in Non-Uniformity Stressed Brittle Materials", J. Am. Ceram. Soc., 47( 6), 28-74 (1964).

14) J.E. Ritter, N. Bandyopadhyay and K. Jakus, "Statistical Reproducibility of the Dynamic and Static Fatigue Experiments", Am. Ceram. Soc. Bull., 60, 798-806 (1981).

15) K. Jakus and J.E. Ritter, "Lifetime Predictions for Ceramics Under Random Loads", Res. Mechanica, 2, 39-52 (1981).

16) (a) J.E. Ritter, P.B. Oates, E. R. Fuller and S.M. Wiederhorn, "Proof Testing of 
Ceramics, I. Experiment", J. Mater. Sci., 15, 2275-81 (1980).

(b) E. R. Fuller, S. M. Widerhorn, J.E. Ritter and P. B. Oates, "Proof Testing of Ceramics, II. Theory", ibid., 2282-95 (1980).

17) J.E. Ritter and S. A. Wulf, "Evaluation of Proof Testing to Assure Against Delayed Failure”, Am. Ceram. Soc. Bull., 57, 186-90 (1978).

18) J. R. McLaren, R. W. Davidge, D. C. L. Cotton, S. A. Haywood and M.E. Robson, "The Mechanical Behaviour of Vitreous-Bonded Aluminas Under StressTime Schedules", Proc. Brit. Ceram. Soc., 26, 67-80 (1978).

19) A. Yamamoto, "Strength Characterstics of Vitrified Grinding Wheels I : Static Fatigue Fracture and Security from Bursting of Rotating Vitrified Grinding Wheels". Bull. Japan Soc. Prec. Engg., 10( 1 ), 1-7 (1976) ; “II, Strength and Static Fatigue of Vitrified Grinding Wheels Under Various Environments", ibid., 10( 2 ), 45-50 and
$63(1976)$

20) J.E. Ritter, J.P. Fahey and T.H. Service, "Cyclic Fatigue Behavior of Resinoid-Bonded Abrasives", to be published.

\section{Biography}

The author received from the Massachusetts Institite of Technology his B.S. degree in 1961 and his M.S. degree in 1962. He received his $\mathrm{Ph} . \mathrm{D}$. degree from Cornell University in 1965. In 1965 the author joined the faculty at the Universtiy of Massachusetts (Amherst) as an assistant professor of mechanical engineering. In 1969 he was promoted to associate professor and in 1976 to professor. In 1983 he took a sabbatical leave in England to do research with Dr. R. Davidge on strength and its variability in alumina. Current research interest include: strength variability, erosion damage, reliability analysis for structural ceramics, and effects of microstructure on fatigue and strength. 